\title{
Assessment of Reproductive Performance and Problems in Crossbred (Holstein Friesian X Zebu) Dairy Cattle in and Around Mekelle, Tigray, Ethiopia
}

\author{
Alemselam Birhanu Mekonnin 1, 2, *, Christopher R. Harlow ${ }^{1}$, Goitom Gidey², Desalew Tadesse ${ }^{2}$, \\ Gidena Desta ${ }^{2}$, Tadesse Gugssa ${ }^{3}$, Simon C. Riley ${ }^{1}$ \\ ${ }^{1}$ MRC Centre for Reproductive Health, CMVM, University of Edinburgh, Edinburgh, UK \\ ${ }^{2}$ College of Veterinary Medicine, Mekelle University, Tigray, Mekelle, Ethiopia \\ ${ }^{3}$ Tigray Bureau of Agriculture and Rural Development, Tigray, Mekelle, Ethiopia
}

Email address:

A.B.Mekonnin@sms.ed.ac.uk (A. B. Mekonnin)

\section{To cite this article:}

Alemselam Birhanu Mekonnin, Christopher R. Harlow, Goitom Gidey, Desalew Tadesse, Gidena Desta, Tadesse Gugssa, Simon C. Riley. Assessment of Reproductive Performance and Problems in Crossbred (Holstein Friesian X Zebu) Dairy Cattle in and Around Mekelle, Tigray, Ethiopia. Animal and Veterinary Sciences. Vol. 3, No. 3, 2015, pp. 94-101. doi: 10.11648/j.avs.20150303.14

\begin{abstract}
A cross sectional study was conducted in and around Mekelle, Tigray, Ethiopia from November 2013 to May 2014 with the aims to assess reproductive performance and prevalence of reproductive problems in crossbred (Holstein Friesian $\mathrm{x}$ Zebu) dairy cattle. A questionnaire survey methodology was used. The study sampled 177 randomly selected dairy farms comprising 1013 crossbred dairy cattle (736 cows and 277 heifers). The mean age at first service, age at first calving, first postpartum estrus and calving interval were 24.8 months, 35.3 months, 114.5 days and 401.5 days, respectively. Prevalence rates of reproductive problems recorded in the study area were anestrus $(37.8 \%)$, repeat-breeding $(21.0 \%)$, dystocia $(11.6 \%)$, retained fetal membranes (11.5\%), endometritis (6.6\%), abortion (6.4\%), prolapsed uterus/vagina (2.9\%), stillbirth (2.0\%) and freemartin $(0.2 \%)$. Incidence of abortion did not vary with parity and stages of gestation. Breeding and the possible causes of missing insemination/mating while animals were in estrus are problematic. In conclusion, this study has revealed that the reproductive performance of crossbred dairy cattle was not optimal, and anestrus, repeat-breeding, dystocia, retained fetal membranes, endometritis and abortion were the major reproductive problems. More effective breeding and reproductive health management should be considered to improve the fertility of this crossbred cattle herd. Awareness and training should be provided to the farming community to improve the productivity in the region.
\end{abstract}

Keywords: Crossbred Dairy Cattle, Reproductive Performance, Reproductive Problems

\section{Introduction}

Ethiopia owns the largest livestock population in Africa and one of the largest in the world, having 52 million cattle, 33 million sheep, 30 million goats, 2.5 million camels and 38 million poultry [1]. About $85 \%$ of the Ethiopian population are engaged in the agricultural sector, which is the backbone of the country's economy, with livestock and its products being important sources of food and income [2]. However, dairying has not been fully exploited and promoted. Cattle play the most important role in the farming economy followed by sheep and goats. This cattle population is primarily of indigenous Zebu type [3]. Barka, Fogera, Boran, Horro, Sheko, Afar and Arsi are also among the Ethiopian local breed cattle which are crossbred with exotic breeds (Holstein Friesian and Jersey). Cattle are well adapted and distributed among diverse ecological conditions and management systems [4].

Dairy cattle production in the country is classified into four major livestock production systems: rural smallholder (mixed crop-livestock) production, pastoral and agro-pastoral production, urban and peri-urban smallholder dairy production, and specialized commercial dairy production systems [2,5]. Infertility is the main problem that affects production in both local and crossbred cows and heifers in Ethiopia [6,7,8]. Consequently, the economic gain for example, calf crops, milk and milk products, from these cows is not satisfactory. Puberty in heifers is usually at 24 months in Zebu X Holstein-Friesian crossbred dairy cattle [7] and, 
heifers are reported to have an extended later age at first calving. Most cows in smallholder farms do not optimally calve every 12 to 13 months after the first calving [6].

Tigray regional state (northern part of Ethiopia) contributes a significant proportion (3.5 million) to the Ethiopian cattle population [1]. There is also an increased demand for milk and milk products in and around Mekelle city [9], due to increased population growth and urbanization. Consequently, the number of people involved in small scale intensive, large scale intensive and small holder dairy farming has increased dramatically in the vicinity of the city. This growth effort is supported by government extension programs through provision of door-to-door Artificial Insemination (AI) service to improve the genetic potential and increase milk production. Despite the effort by government to enhance the dairy sector, there is limited ongoing livestock research, particularly on assessment of reproductive and productive performance and reproductive problems of dairy cattle. Therefore, the objectives of this study were to assess reproductive performance and to study the prevalence of reproductive problems of crossbred (Zebu x Holstein Friesian) dairy cattle in and around Mekelle, Tigray, Ethiopia.

\section{Materials and Methods}

\subsection{Study Area}

The study was conducted from November 2013 to May 2014 in and around Mekelle city, which is the largest city in northern Ethiopia, and the capital city of Tigray. It is located at $39^{\circ} 29^{\circ} \mathrm{E}$ and $13^{\circ} 30^{\circ} \mathrm{N}$ at an altitude of 2000 metres above sea level. The climate of the study area conforms to that of Ethiopian Highlands. The mean annual rainfall is $619 \mathrm{~mm}$, which is bimodal with short rainy seasons occurring from March to May and from mid-September to February. The annual minimum and maximum temperature is $11.8^{\circ} \mathrm{C}$ and $29.9^{\circ} \mathrm{C}$, respectively [10].

\subsection{Study Methodology}

\subsubsection{Study Farms and Animals}

The number of farms sampled in the study was determined by $\mathrm{N}=0.25 / \mathrm{SE}^{2}$, where $\mathrm{N}=$ number of sampled farms, $\mathrm{SE}=$ Standard error [11]. A list of 210 farms housing crossbred dairy animals were considered as the sampling frame. From this, 173 farms were selected using systematic random sampling. Considering standard error of 0.038 with $95 \%$ confidence interval as follows, $\mathrm{N}=0.25 /(0.038)^{2}=173$. In total, 177 dairy farms were included in the survey to enhance precision. These farms housed 736 crossbred (Zebu $x$ Holstein Friesian) dairy cows and 277 crossbred dairy heifers aged two years or above. They also housed 55 crossbred dairy bulls and 398 crossbred dairy calves during the study period.

\subsubsection{Questionnaire Data Collection and Analysis}

The questionnaire (Appendix 1) was translated into local language (Tigrigna) and piloted beforehand. A cross-sectional survey was used to collect information on reproductive performance and assess the common reproductive problems of crossbred dairy cows and heifers. Farm owners, attendants, managers, and veterinary professionals were given a short briefing about the overall aims of the study. They were asked to complete the questionnaire survey information regarding age at first service, age at first calving, calving interval, first post-partum estrus, reproductive health problems, breeding history (AI, natural mating, parity) and other related questions including the year of farm establishment. Data was analysed using two tailed Fisher's exact test where a $p$ value of $<0.05$ was considered significant [12].

\section{Results}

\subsection{Reproductive Performance}

The average ages at first service and at first calving were 24.8 months (range 10 to 48 months) and 35.3 months (range of 21 to 57 months), respectively. First postpartum estrus and calving interval are indicated in Table 1.

\subsection{Common Reproductive Problems}

Anestrus, repeat-breeding, dystocia, retained fetal membranes (RFM), endometritis and abortion were the major reproductive problems cited by farmers/attendants or veterinarians in crossbred dairy cattle, with prevalence indicated in Table 2. Among 177 farms, 163 (92.1\%) farms were affected by one or multiple reproductive problems. There were similar incidences of abortion in cows and heifers based on stages of pregnancy (Table 3). Overall incidence of abortion in crossbred cattle in first, second and third trimesters were, $17.5 \%, 42.1 \%$ and $40.4 \%$, respectively. There was significantly higher $(\mathrm{p}<0.05)$ incidence of anestrus in heifers than cows. Conversely, higher incidence $(\mathrm{P}<0.05)$ of dystocia and retained placenta was recorded in multiparous than in primiparous cattle (Table 2).

The common breeding method in the study area is mixed AI and natural mating by bull (Table 4). Among 177 farms, 68 (38.4\%) farms had shown missing insemination/mating due to various factors. Although animals showed typical signs of estrus (including clear vaginal discharge, restlessness, mounting other cows, mounted by other cows), owners failed to get their animals mated or inseminated. Major causes of missed insemination recorded are absence of AI technicians when called to inseminate, or arriving very late $(33.8 \%)$, poor animal condition (19.1\%), inattentiveness $(11.8 \%)$ and reproductive/other health problems $(8.8 \%)$.

Table 1. Reproductive performance of crossbred dairy cattle in the study area.

\begin{tabular}{lll}
\hline Variable & Range & Mean \pm SD \\
\hline Age at first service (months) & 10 to 48 & $24.8 \pm 6.6$ \\
Age at first calving (months) & 21 to 57 & $35.3 \pm 6.3$ \\
First postpartum estrus (days) & 9 to 480 & $114.5 \pm 73.7$ \\
Calving interval (days) & 302.9 to 759.2 & $401.5 \pm 73.0$ \\
\hline
\end{tabular}


Table 2. The relative prevalence of major reproductive problems of crossbred dairy cows and heifers in and around Mekelle.

\begin{tabular}{lllll}
\hline Reproductive problems & Total incidence* & Incidence in multiparous cows* & $\begin{array}{l}\text { Incidence in heifers/ primiparous } \\
\text { heifers* }\end{array}$ & $\begin{array}{l}\text { P-value (Fisher's } \\
\text { exact test) }\end{array}$ \\
\hline Anestrus" & $336(37.8)$ & $225(31.5)$ & $111(63.1)$ & $<0.0001$ \\
Repeat-breeding" & $187(21.0)$ & $153(21.4)$ & $34(19.3)$ & 0.6058 \\
Dystocia & $103(11.6)$ & $92(12.9)$ & $11(6.2)$ & 0.0122 \\
RFM & $102(11.5)$ & $99(13.9)$ & $3(1.7)$ & $<0.0001$ \\
Endometritis & $59(6.6)$ & $52(7.3)$ & $7(4.0)$ & 0.1293 \\
Abortion & $57(6.4)$ & $50(7.0)$ & $7(4.0)$ & 0.1698 \\
Stillbirth & $18(2.0)$ & $17(2.4)$ & $1(0.6)$ & 0.2259 \\
Prolapsed uterus/ vagina & $26(2.9)$ & $26(3.6)$ & 0 & - \\
Freemartin & $2(2.0)$ & - & $2(1.1)$ & - \\
Total & 890 & 714 & 176 & \\
\hline
\end{tabular}

Anestrus and repeat-breeding were compared between multiparous cows and heifers; whereas, dystocia, retained fetal membranes (RFM), endometritis, abortion, stillbirth and prolapsed uterus/vagina were compared between multiparous cows and primiparous heifers; freemartin associated with heifers. Animals were reported to have one or multiple exposures to a single or to multiple problems. *Values in parentheses are percentages. P-value of $<0.05$ considered significant.

Table 3. Prevalence of abortion based on stages of pregnancy versus parity in crossbred dairy cattle.

\begin{tabular}{|c|c|c|c|c|}
\hline \multirow{2}{*}{$\begin{array}{l}\text { Stage of } \\
\text { gestation }\end{array}$} & \multirow{2}{*}{$\begin{array}{l}\text { Total } \\
\text { aborted* }\end{array}$} & \multicolumn{2}{|c|}{ Abortion based on parity } & \multirow{2}{*}{$\begin{array}{l}\text { P-value } \\
\text { (Fisher's } \\
\text { exact test) }\end{array}$} \\
\hline & & $\begin{array}{l}\text { Multiparo } \\
\text { us cows* }\end{array}$ & $\begin{array}{l}\text { Primiparo } \\
\text { us heifers* }\end{array}$ & \\
\hline 1 st trimester & $10(17.5)$ & $7(14.0)$ & $3(42.9)$ & 0.0949 \\
\hline 2nd trimester & $24(42.1)$ & $23(46.0)$ & $1(14.2)$ & 0.2197 \\
\hline 3rd trimester & $23(40.4)$ & $20(40.0)$ & $3(42.9)$ & 1.0000 \\
\hline Total & $57(100)$ & $50(100)$ & $7(100)$ & 0.1698 \\
\hline
\end{tabular}

*Values in parentheses are percentages. $\mathrm{P}$ value of $<0.05$ considered significant.

Table 4. Breeding practises with crossbred cattle in the study area.

\begin{tabular}{ll}
\hline Breeding methods & Number of farms* \\
\hline Artificial insemination (AI) & $61(34.5)$ \\
Natural mating (bull) & $46(26)$ \\
Mixed AI and bull & $70(39.5)$ \\
Total & $177(100)$ \\
\hline
\end{tabular}

*Figures in parentheses are percentages.

\section{Discussion}

\subsection{Reproductive Performance}

\subsubsection{Age at First Service and Age at First Calving}

In the current study, the age at first service and calving were in accordance with previous studies in small holder dairy farms in Oromia region, Ethiopia [8]. Similar ages were also recorded in crossbred cattle at first service in Gondar town [13] and in Dire Dawa [14], Ethiopia. Ages at first service and first calving were similar to recent studies in small scale farms in and around Mekelle, Ethiopia [15]. Further, comparable ages at first calving were recorded in previous studies in urban and in peri-urban crossbred dairy cattle farms, in central Tigray [16], and in crossbred cattle in Tanzania [17,18]. However, later age at first calving was recorded in the present study than in crossbred (Arsi breed X
Jersey, and Arsi breed X Holstein Friesian) cattle in Asella, Ethiopia $[19,20]$. The current study showed comparatively earlier age in crossbred dairy heifers at first calving than in Zimbabwe [21], other parts of Ethiopia [6] and in Malawi [22]. Heifers can be bred when they attain $60 \%$ of their adult body weight [23]. For a dairy farm to be profitable there should be a focus on heifer's timely growth and conception. Age at puberty and calving are highly related to body weight of the heifers [24].

\subsubsection{First Postpartum Estrus and Calving Interval}

Comparatively longer postpartum estrus was recorded in the present study than in Oromia region, Ethiopia [8]. In contrast, the present study showed shorter postpartum estrus period compared to studies in Abernosa Ranch [25] and in small scale farms in and around Mekelle, Ethiopia [15]. In the present study, the calving interval was similar to previous reports $[8,19]$. In contrast, the present findings revealed shorter calving intervals compared to previous studies in central part of Ethiopia [6], Abernisa Ranch, Ethiopia [17], small scale dairy farms in and around Mekelle, Ethiopia [15], Malawi [22] and Tanzania [18]. Unlike the present study and other reports in crossbred (Zebu x Holstein Friesian) dairy cattle, pure Zebu (Bos indicus) cattle have a much longer calving interval [26]. Farmers/attendants or farm managers in the present study were asked if they had observed pregnancy overdue. They responded indicating animals bearing male calves tend to have 1 to 2 weeks longer gestation periods compared to female calves, which is in accordance with previous reports [8].

\subsection{Prevalence of Reproductive Problems}

Anestrus was found to be the most prevalent reproductive problem followed by repeat-breeding. This is in contrast to a previous questionnaire survey [27]. The present study also demonstrated high incidence of anestrus in comparison with a study in crossbred cattle in Bangladesh [28]. Our study indicates that repeat-breeding was a major problem affecting 
fertility of animals in the study area. High incidence of repeat breeding could be due to lack of nutrition, improper insemination and timing of AI and poor semen quality [29]. Our incidence of repeat breeding is comparatively higher than previous reports from Ethiopia in crossbred cows around Bedelle [27], East Showa [29], in indigenous Boran breed cows in Borena Zone [30], in crossbred cows/heifers in Mekelle city, Ethiopia [31] and in crossbred cows in Bangladesh [28]. Conversely, the present study showed lower incidence of repeat-breeding than incidences in Goa, India [32].

Dystocia is one of the major reproductive problems in crossbred dairy cattle in and around Mekelle, and is comparatively higher than in previous reports from south western [27] and other parts of Ethiopia [29]. Our findings are in contrast to previous studies where incidence of dystocia was higher in multiparous cows compared to primiparous heifers [33]. Incidence of dystocia in primiparous heifers was less than in multiparous cows. The possible causes of dystocia reported by the farmers and veterinarians were failure of cervical dilatation, fetal oversize, twinning, abnormal presentation, position and posture of the fetus, uterine inertia, hypocalcaemia and obesity of the dam.

Prevalence of retained fetal membranes was in agreement with previous studies conducted in south western part of Ethiopia [27]. Contrary to our finding, lower incidence was reported in crossbred dairy cows in other part of Ethiopia [29] and crossbred cows in Bangladesh [28]. The higher incidence of retained fetal membranes in multiparous cows than primiparous heifers were consistent with previous studies in Israel [34]. The reason retained fetal membranes was higher in multiparous cows could be due to previous exposure to reproductive problems or other health problems and nutritional deficiencies.

The prevalence of endometritis in the present study was comparatively lower than previous reports in crossbred cows in other part of Ethiopia [27]. However, it was higher than reports in East Shoa, Ethiopia [29] and Bangladesh [28].

Abortion is one of the major causes of economic losses in the cattle industry. Overall incidence of abortion in the current survey was comparatively higher than in reports by Esheti and Moges [29], although lower than in other studies of crossbred cows elsewhere in Ethiopia [27]. Abortion could be due to metabolic or hormonal abnormalities, nutritional deficiencies, trauma, toxicities, or infectious agents $[35,36]$. In the present study, although results were not significant, there was comparatively higher prevalence of stillbirth in calves born from multiparous cows to calves born from primiparous heifers. Contrary to our survey, it is speculated that the occurrence of assisted calving is 2.5 times higher in primiparous heifers than multiparous cows and that there is a high incidence of stillbirth [37]. This represents an area for future study.

The exact cause of prolapsed uterus is not clear [38] although high estrogen has been proposed to cause prolapsed vagina [39]. Delayed intervention in cases of uterine prolapse may cause fatal septicaemia [40]. Freemartinism is not a major reproductive problem in crossbred cattle in and around Mekelle, although it is one of the causes of anestrus and sterility in heifers. The occurrence of freemartinism reaches $90-97 \%$ in twin pregnancies in cattle $[41,42]$.

This study has noted high incidence of missed insemination or mating. The use of AI is encouraged by government, with a bull rearing and semen collection centre being established in Mekelle, and few farmers have their own crossbred dairy bulls for breeding purposes. When animals are not bred when they come to estrus, this will inevitably result in heifers with a long age at first service and first calving, and cows with a longer calving interval, hence a decreased calf crop or replacement heifers. Strategies to improve breeding management should be developed to achieve one calf per year and therefore improve economic development in dairy production.

In conclusion, this study has noted that the reproductive performance of crossbred cattle was not optimal, and that anestrus, repeat-breeding, dystocia, retained fetal membranes, endometritis and abortion were the major reproductive problems affecting fertility of crossbred dairy cattle in and around Mekelle, Tigray, Ethiopia. Hence, effective breeding and reproductive health management should be considered as a means to improve fertility of crossbred cattle. Furthermore, awareness and training should be given to the farming community to improve productivity for the dairy industry in the region.

\section{Acknowledgments}

The authors acknowledge School of Clinical Sciences, College of Medicine and Veterinary Medicine, University of Edinburgh for supporting Alemselam Birhanu Mekonnin and for funding the study. Special thanks would be offered to Mekelle University, College of Veterinary Medicine for the offer of transport and other facilities and support. We also thank the farmers, farm attendants, farm managers, AI technicians and veterinary professionals working in dairy farms who agreed to participate in the survey.

\section{Appendix 1}

Pre-screening questionnaire given to livestock owners/ farm managers to study the prevalence of reproductive diseases/ problems in crossbred cows/heifers in and around Mekelle, Tigray, Ethiopia.

1. Name of the farm or farm owner

2. Address of the farm: ; phone no.

3. When was the farm established? $\square 1-5$ years $\square 6-10$ years $\square>10$ years 
4. Type of farm: $\square$ Intensive $\square$ Semi-intensive $\square$ Extensive

5. Number of cattle in the farm (owned)?
a. No. of Cows
c. No. of bulls

b. No. of heifers d. No. of calves

6. Types of feed cows or heifers are fed:

$\square$ Hay $\square$ Straw $\square$ Concentrate $\square$ Concentrate and hay or straw

7. How many times do animals get feed per day?

8. Do animals get water regularly? ; how many times a day?

9. Age of cows and/or heifers and parity (years):

Cow 1. (parity ); heifer 1 .

Cow 2. (parity ); heifer 2.

Cow 3. (parity ); heifer 3 .

Cow 4. (parity ); heifer 4.

Cow 5. (parity ); heifer 5 .

Cow 6. (parity ); heifer 6 .

Cow 7. (parity ); heifer 7 .

Cow 8 . (parity ); heifer 8 .

Cow 9. (parity ); heifer 9 .

Cow 10. (parity ); heifer 10

10. What is the number of pregnant cows/ heifers in the farm?
A) Cows: (trimester: $1 \mathrm{st} ; \ldots 2 \mathrm{nd}$ 3rd)
B) Heifers: (trimester: 1st; 2nd; $3 \mathrm{rd})$

11. Method of insemination? Natural AI Both

12. Number of animals in estrous now? A) Cows: ; B) Heifers:

13. How many lactating cows do you have?

14. What is the number of anestrus animals in the farm? A) Cows? ; B) Heifers:

15. Were any of your cattle encountered reproductive diseases or problems in the past? $\square$ Yes $\square$ No 16. If yes, what reproductive diseases or problems were observed?

\section{Did any of your cows suffer from abortion? $\square$ Yes $\square$ No}

18. If yes, what month of the pregnancy abortion was occurred?
a. before 3 months
c. over 6 months
b. 3 to 6 months
d. $\mathrm{a}, \mathrm{b}$ and $\mathrm{c}$

19. Did any of your cows encounter pregnancy overdue in the past? $\square$ Yes $\square$ No

If yes, how many months was the cow pregnant before it was given veterinary assistance?

? Number of cows diagnosed positive?

20. Did any of your cows or heifers give birth to a dead calve at a normal gestation length (9 months) in the past? 
If yes, how many cows?

21. Did any of your cows suffer from dystocia in the past? $\square$ Yes $\square$ No

If yes, how many of your cows suffered from dystocia?

22. Did any of your cows suffer from endometritis in the past? $\square$ Yes $\square$ No

If yes, no of cows or heifers suffered from endometritis?

23. Did any of your cows or heifers suffer from vaginal, cervical or uterine prolapse in the past?

$\square$ Yes $\square$ No

If yes, number of cows or heifers with vaginal prolapse? ; Cervical prolapse? or uterine prolapse?

24. Did any of your cows encounter retained fetal membranes in the past?

How did you solve the problem?

25 . Have any of your cows or heifers been repeater (repeat breeder)?

If yes, what do you think the cause/s for the animal to come back in to estrus again?

What measure did/do you take to get the animal pregnant?

26. Did any of your cows suffer from metritis in the past?

If yes, what treatment did the cow get?

What was the effect of the treatment in the reproductive status of the cow after that?

27. Did any of your animals come to estrus, but missed insemination or mating in the past? $\square$ Yes $\square$ No

If yes, why was the animal not inseminated or mated?

a. Lack of bull

b. Lack of AI technician

c. Lack of means of communication to AI technician

d. Called AI technician, but did not come to inseminate or did come very late

e. Reproductive tract problem

f. Size of the animal was very small to breed

g. Lack of nutrition

h. All or some of the above causes

28. Did any of your animals suffer from any health problem other than reproductive health?

If yes, please describe the disease and signs the animals showed.

29. What is your future plan to improve the reproductive performance of your animals?

30. What do you think the government (agriculture, universities, etc.) and private sectors should do to support improve fertility of your animals?

31. Do you have any comment?

Thanks!! 


\section{References}

[1] CSA (2012). (Central Statistics Agency of Ethiopia). http://www.csa.gov.et.

[2] IBC (Institute of Biodiversity Conservation), 2004. The state of Ethiopia's farm animal genetic resources-country report. A contribution to the First Report on the State of the Worlds Animal Genetic Resources. ftp://ftp.fao.org/docrep/fao/010/a1250e/annexes/CountryRepo rts/Ethiopia.pdf.

[3] NABC (2010). Fact Sheet: Livestock Ethiopia; Livestock in Ethiopia and opportunity analyses for Dutch investment September 2010 NABC.

[4] Lobago, F., Bekana, M., Guftafsson, H. and Kindahl, H. (2006). Reproductive performance of dairy cows in smallholder production system in Selalle, Central Ethiopia. Trop. Anim. Health Prod. 38: 333-342.

[5] Lobago, F. (2007). Reproductive and lactation performance of dairy cattle in the Oromia Central Highlands of Ethiopia with special emphasis on pregnancy period. Doctoral thesis Swedish University of Agricultural Sciences, Uppsala.

[6] Shiferaw, Y., Tenhagen, B. A., Bekana, M. and Kassa, T. (2003). Reproductive performance of crossbredd cows in different production systems in the central highlands of Ethiopia. Trop. Anim. Health and Prod. 35: 551-561.

[7] Duguma, B., Kechero, Y. and Janssens, G-P.J. (2012). Productive and Reproductive Performance of Zebu X Holstein-Friesian Crossbred Dairy Cows in Jimma Town, Oromia, Ethiopia. Global Veterinaria 8(1): 67-72.

[8] Dinka H. (2013). Reproductive performance of crossbred dairy cows under smallholder condition in Ethiopia. AJDFMP 1(5): 101-103.

[9] Fisseha, N. E. (2010). Determinants, challenges and prospects of dairy production and marketing in Mekelle city.Master's Thesis.Mekelle University, Mekelle, Ethiopia.

[10] BoPED (2011). (Bureau of Planning and Economic Development), Tigray, Ethiopia.

[11] Arsham, H. (2005). Questionnaire design and surveys sampling, 9th ed. http://home.ubalt.edu/ntsbarsh/statdata/Surveys.htm (Retrieved July15, 2012).

[12] Prism 6.0 for Windows, GraphPad Inc., La Jolla, California, USA, http://www.graphpad.com. (Accessed online 23 November 2014).

[13] Nuraddis I., Shebir A. and Shiferaw M. (2011). Assessment of Reproductive Performance of Crossbred Cattle (Holstein Friesian X Zebu) in Gondar Town.Global Veterinaria 6(6): 561-566.

[14] Mureda, E. and Mekuriaw, Z. (2007). Reproductive Performance of Crossbred Dairy Cows in Eastern lowlands of Ethiopia. Livestock Research for Rural Development. Volume 19, Article number 161. http://www.lrrd.org/lrrd19/11/mure19161.htm.

[15] Kumar, N. and Tkui, K. (2014). Reproductive performance of crossbred dairy cows in Mekelle, Ethiopia. Sci. J. Anim Sci. 3(2): $35-40$

[16] Weldeslasse, G. T., Zeleke, Z. M. and Gangwar, S. K (2012): Reproductive and productive performance of dairy cattle in Central Zone of Tigray, Northern Ethiopia. I.J.A.B.R. 2(1): 58-63.

[17] Haile-mariam M., Banjaw K., Gebremeskel J., Ketema T. (1993). Productivity of Boran Cattle and their Friesian crosses at Abernossa Ranch, Ethiopia. I. Reproductive performance and prevailing mortality. Trop. Anim. Health Prod. 25: 239248.

[18] Asimwe, L. and Kifaro, G. C. (2007). Effect of breed, season, year and parity on reproductive performance of dairy cattle under smallholder production system in Bukoba district, Tanzania. Livestock Research for Rural Development 19. http://www.lrrd.org/lrrd19/10/asim19152.htm.

[19] Negussie E., Brannang E., Banjaw, K. and Rottmann, O. U. (1998).Reproductive performance of dairy cattle at Assella livestock farm.Arsi. Ethiopia. I: Indigenous cows versus their F1 crosses. J. Anim. Breed. Genet. 115: 267-280.

[20] Yifat D., Kelay B., Bekana M., Lobago F., Gustafsson H. and Kindahl H. (2009). Study on reproductive performance of crossbred dairy cattle under smallholder conditions in and around Zeway, Ethiopia. Livestock Research for Rural Development. 21(88). Retrieved April 15, 2015, from http://www.lrrd.org/lrrd21/6/yifa21088.htm.

[21] Masama, E., Kusina, K. T., Sibanda, S. and Majoni, C. (2003). Reproduction and lactation performance of cattle in a smallholder dairy system in Zimbabwe. Trop. Anim. Health Prod. 35: 117-129.

[22] Agyemang, K. and Nkhonjera, L. P. (1990). Productivity of Crossbred Cattle on Smallholder Farms in Southern Malawi. Trop. Anim. Health Prod. 22: 9-16.

[23] Hammond, J. (1960), Farm animals their breeding, growth and inheritance. Arnold, London. 49(5): 46-473.

[24] Moore, R. K., Kennedy, B. W., Schaefer, L. H. and Moxley, J. E. (1990). Relationship between reproduction traits, age and body weight at calving and days dry in first lactation Ayrshires and Holsteins. J. Dairy Sci. 73: 835-842.

[25] Bekele T., Kasali O. B. and Alemu T. (1991). Reproductive problems in crossbred cattle in Central Ethiopia. Anim. Prod. Sci. 26: 41-49.

[26] Mukasa-Mugerwa, E. (1989). A review of reproductive performance of female Bos indicus (Zebu) cattle. International Livestock Centre for Africa (ILCA), monograph, Addis Ababa, Ethiopia.

http://www.ilri.org/InfoServ/Webpub/Fulldocs/X5442e/x5442 $\mathrm{e} 00 . \mathrm{htm}$

[27] Bitew, M. and Prasad, S. (2011). Study on Major Reproductive Health Problems in Indigenous and Cross Breed Cows in and Around Bedelle, South West Ethiopia. J. Anim. Vet. Advan. 10(6): 723-727.

[28] Al-Maruf, A., Paul, A. K., Bonaparte, N., Bhuyian, M. H. and Shamsuddin, M. (2014). Reproductive Disorders that Limits the Reproductive Performances in Dairy Cows of Bangladesh. J. Emb. Trans. 29(2): 189-194. 
[29] Esheti, G. and Moges, N. (2014). Major Reproductive Health Disorders in Cross Breed Dairy Cows in Ada'a District, East Shoa, Ethiopia. Global Veterinaria 13(4): 444-449.

[30] Benti, A. D. and Zewdie, W. (2014). Major reproductive health problems of indigenous Borena cows in Ethiopia. J. Adv. Vet. Anim. Res. 1(4): 182-188.

[31] Mandefro, M. and Negash, G. (2014). Repeat Breeder Syndrome in Dairy Cows: Influence of Breed and Age on Its Prevalence. World J. Agric. Sci. 10 (4): 200-203.

[32] Chakurkar, E. B., Barbuddhe, S. B. and Sundaram, R. N. S. (2008). Infertility in farm animals: causes and remedies. Technical Bulletin No: 15, ICAR Research Complex for Goa (Indian Council of Agricultural Research), Ela, Old Goa403402, Goa, India. pp. 1-14.

[33] Johanson, J. M. and Berger, P. J. (2003). Birth weight as a predictor of calving ease and perinatal mortality in Holstein cattle. J. Dairy Sci. 86: 3745-3755.

[34] Eger, S., Drori, D., Kadoori, I., Miller, N. and Schindler, H. (1985). Effects of Selenium and Vitamin E on Incidence of Retained Placenta. J. Dairy Sci. 68: 2119-2122.

[35] Ortega-Mora, L. M., Gottstein, B., Conraths, F. J. and Buxton, D. (2007). "Ruminants: Guidelines for Diagnosis and Control in Farm Protozoal Abortion. CAB International, UK.

[36] Givens, M. D. (2006). A clinical, evidence-based approach to infectious causes of infertility in beef cattle. Theriogenology 66: 648-654.

[37] Olson, K. M., Cassell, B. G., McAllister, A. J., and Washburn, S. P. (2009). Dystocia, stillbirth, gestation length, and birth weight in Holstein, Jersey, and reciprocal crosses from a planned experiment. J. Dairy Sci. 92: 6167-6175.

[38] Noakes, E. D., Parkinson, T. J. and England, G. C. W. (2001a). Post parturient prolapse of the uterus. Chapter 19. In: Arthur's Veterinary Reproduction and Obstetrics. 8th ed. Harcourt (India) Pvt. Ltd., New Delhi. pp. 333-338.

[39] Roberts, S. J. (1998). Vaginocervical prolapse. In: Veterinary Obstetrics and Genital Diseases (Theriogenology). 2nd ed. [Indian reprint] CBS Publishers and Distributors, New Delhi, India. pp. 196-198.

[40] Bhattacharyya, H. K., Peer, F. U., Buchoo, B. A. and Ansari, M. M. (2007). Management of uterine prolapse in cattle of Kashmir. Indian Vet. J. 84: 744-745.

[41] Esteves, A., Båge, R. and Payan-Carreira, R. (2012). Freemartinism in Cattle, Ruminants: Anatomy, Behavior and Diseases, Chapter: Chapter 7, Nova Science Publishers Inc, pp. 99-120.

[42] SDDP (1999). Calf and heifer rearing. SDDP Extension Manual, Smallholder Dairy Development Project. Ministry of Agriculture. August 1999 Addis Ababa, Ethiopia. 3: 1-15. 